\title{
Schistosomal glomerulopathy and changes in the distribution of histological patterns of glomerular diseases in Bahia, Brazil
}

\author{
Washington Luis Conrado dos-Santos ${ }^{1,2} /{ }^{+}$, Glória Maria Maranhão Sweet ${ }^{1}$, \\ Marília Bahiense-Oliveira' ${ }^{2}$, Paulo Novis Rocha ${ }^{3}$ \\ ${ }^{1}$ Centro de Pesquisas Gonçalo Moniz-Fiocruz, Rua Waldemar Falcão 121, 40296-710 Salvador, BA, Brasil \\ Escola Bahiana de Medicina e Saúde Pública, Salvador, BA, Brasil \\ ${ }^{3}$ Faculdade de Medicina da Bahia, Universidade Federal da Bahia, Salvador, BA, Brasil
}

Distinct patterns of glomerular lesions, including membranoproliferative glomerulonephritis and focal segmental glomerulosclerosis, are associated with infection by Schistosoma mansoni or Schistosoma japonicum. Evidence suggests that immune complex deposition is the main mechanism underlying the different forms of schistosomal glomerulonephritis and that immune complex deposition may be intensified by portal hypertension. The relationship between focal segmental glomerulosclerosis and schistosomiasis remains poorly understood. A clinicopathologic classification of schistosomal glomerulopathies was proposed in 1992 by the African Association of Nephrology. In Brazil, mass treatment with oral medications has led to a decrease in the occurrence of schistosomal glomerulopathy. In a survey of renal biopsies performed in Salvador, Brazil, from 2003-2009, only 24 (4\%) patients were identified as positive for S. mansoni infection. Among these patients, only one had the hepatosplenic form of the disease. Focal segmental glomerulosclerosis was found in seven patients and membranoproliferative glomerulonephritis was found in four patients. Although retrospective studies on the prevalence of renal diseases based on kidney biopsies may be influenced by many patient selection biases, a change in the distribution of glomerulopathies associated with nephrotic syndrome was observed along with a decline in the occurrence of severe forms of schistosomiasis.

Key words: schistosomiasis - Schistosoma mansoni - Schistosoma japonicum - mesangiocapillary glomerulonephritis kidney diseases - focal segmental glomerulosclerosis

Schistosomal glomerulopathy was classified as a clinicopathological entity following the publication of a series of studies published mainly by Brazilian researchers in the 1960s and 1970s. The evidence supporting the classification of schistosomal glomerulopathy as a distinct disease comes from the following observations: (i) clinical and laboratory signs of renal disease are more prevalent in patients with hepatosplenic schistosomiasis than in patients with other clinical forms of Schistosoma mansoni infection or in non-infected controls (reviewed by Andrade \& de Queiroz 1968), (ii) the frequency of severe glomerular lesions is higher in patients with hepatosplenic schistosomiasis than in patients with hepatic cirrhosis or other unrelated diseases (Andrade \& de Queiroz 1968), (iii) schistosomal glomerulopathy has been experimentally reproduced in different animal species infected with S. mansoni or Schistosoma japonicum (De Brito et al. 1971, Andrade \& Susin 1974, Cavallo et al. 1974), (iv) schistosomal antigen-containing immune complexes (IC) have been identified in the kidneys of $S$. mansoni or S. japonicum-infected patients and experimental animals, even in non-hepatosplenic forms of the disease (Hoshino-Shimizu et al. 1975, van Marck et al. 1981) and (v) a sequential temporal relationship between

Financial support: PPSUS (4785/2009), CPqGM-Fiocruz

+Corresponding author: wluis@bahia.fiocruz.br

Received 18 April 2011

Accepted 8 July 2011
Schistosoma infection and the appearance of renal lesions has been observed in experimental studies and is suggested by follow-up studies of transplant patients (Falcao \& Gould 1975). The overall frequency of glomerulopathy was $12 \%$ in patients with hepatosplenic schistosomiasis compared with $5.6 \%$ in the global population of patients autopsied in a general hospital (Andrade et al. 1971). A similar frequency (12.7\%) of renal disease was reported in a recent study involving 63 patients with hepatosplenic schistosomiasis from Minas Gerais, Brazil (Rodrigues et al. 2010).

A variety of anatomopathological patterns of glomerular lesions have been associated with schistosomal glomerulopathy, due mainly to the intensity of infection, the emergence of portal hypertension and the association with infections by other pathogens (van Marck et al. 1977, Ramos \& Andrade 1987, Zeid et al. 1994, Chisty et al. 2002, Barsoum 2004). The diversity observed among the lesions associated with schistosomiasis motivated a clinicopathologic classification of schistosomal glomerulopathies, endorsed in 1992 by the African Association of Nephrology (AFRAN) (Barsoum 2004), that recognized the five categories of glomerular diseases shown in Table I.

Class I (mesangioproliferative glomerulonephritis) may be the most prevalent form of schistosomal glomerulopathy seen in patients with hepato-intestinal or hepatosplenic schistosomiasis (Sobh et al. 1990). Patients with this form of the disease are clinically normal or they may present mild proteinuria or nephrotic syndrome. Mesangial and paramesangial deposits with mesangial cell proliferation are observed in the glomeruli. Class II 
TABLE I

Histological classification of schistosomal glomerulopathy ${ }^{a}$

\begin{tabular}{ll}
\hline Class & Histological pattern and associations \\
\hline I & Mesangial glomerulonephritis \\
& Mesangial deposition of immune complexes with or without mesangial cell proliferation \\
II & Exudative glomerulonephritis \\
& Proliferation of endothelial and mesangial cells, neutrophil \\
& Infiltrate; usually associated with co-infection by Salmonella spp \\
& Membranoproliferative glomerulonephritis (type I or III) \\
III & Mesangial and endothelial cell proliferation and a double contour of the glomerular basement membrane; massive \\
& immune complex deposition in the mesangium and in the sub-endothelial and occasionally in the sub-epithelial \\
& aspects of the glomerular basement membrane \\
& Focal segmental glomerulosclerosis \\
IV & Sclerosis and adherence of glomerular segments to the Bowman capsule seen in a variable number of glomeruli \\
& Amyloidosis
\end{tabular}

$a$ : recommended by the African Association of Nephrology (Barsoum 2004).

(exudative glomerulonephritis) occurs in the presence of concomitant infection by Schistosoma and Salmonella species. Patients may have nephrotic or nephritic syndrome and a proliferative glomerulonephritis with neutrophil infiltration of the glomeruli (Bassily et al. 1976, Rocha et al. 1976, Martinelli et al. 1992). Class III (membranoproliferative glomerulonephritis) and Class IV (focal segmental glomerulosclerosis) represent the patterns of glomerular lesion that are most consistently associated with the hepatosplenic form of schistosomiasis in Brazil. Both are associated with nephrotic syndrome and with progression to chronic kidney disease. Class V (renal amyloidosis) has been reported in Africa, but its association with $S$. mansoni infection in Brazil remains controversial (Sadigursky \& Andrade 1976, Strausbaugh et al. 1978). Recently, another class (Class VI) has been proposed as an addition to the AFRAN classification of schistosomal glomerulopathy. This lesion consists of mesangial proliferation associated with apoptotic transient cellular infiltrations, amyloidosis and cryoglobulin deposition, which are attributed to the combined effect of infection by Schistosoma spp and hepatitis C virus (Barsoum 2004).

The suggested mechanism underlying schistosomal glomerulonephritis is immune complex deposition in the mesangial, sub-endothelial and sub-epithelial regions of the glomerulus. IC of IgG, IgM and complement, together with parasite antigens and $\operatorname{IgA}$ aggregates, have been identified in the glomeruli of both human and experimental animals with mesangioproliferative and membranoproliferative glomerulonephritis. Immune complex deposition may be intensified by the portosystemic shunt secondary to portal hypertension (Fig. 1) (van Marck et al. 1979). Co-infection by Salmonella or hepatitis B and C viruses, other co-morbidities and genetic background may add complexity to the pattern of glomerular lesions (Jones 1977, Zeid et al. 1994, Abdul-Fattah et al. 1995, Barsoum 2004). Although immune complex deposition has been consistently demonstrated in schistosomal glomerulo-

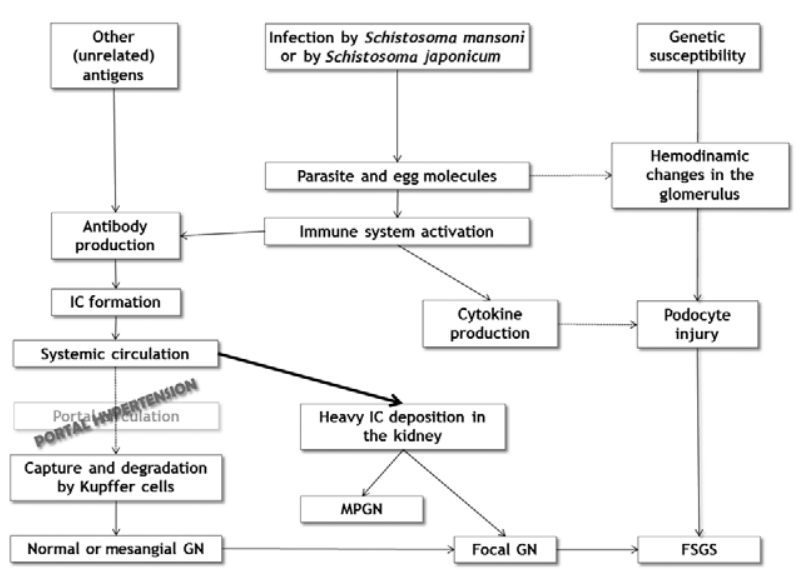

Fig. 1: proposed mechanisms of glomerular lesion development in schistosomal glomerulopathy. In normal subjects, circulating immune complexes (IC) are rapidly cleared from circulation by mononuclear phagocytic cells, particularly Kupffer cells in the liver. Some of these complexes may reach the kidney, leading to mesangial glomerulonephritis (GN) in patients with non-hepatosplenic forms of schistosomiasis. As portal hypertension develops in hepatosplenic schistosomiasis, massive loads of IC containing both schistosomal and non-schistosomal antigens enter the systemic circulation and are deposited in the kidney, leading to other forms of GN [i.e. membranoproliferative GN (MPGN)]. Focal segmental glomerulosclerosis (FSGS) may result from healed lesions of focal GN or a combination of factors that potentially contributes to podocyte injury.

nephritis, the relationship between focal segmental glomerulosclerosis and schistosomiasis remains unclear (Fig. 1). The genetic background of a predominantly Afrodescendant population infected by the parasite has been proposed as a possible explanation (Lopes et al. 2002).

Schistosomal glomerulopathy is more frequently associated with $S$. mansoni and $S$. japonicum infection. In Brazil, mass treatment with oral medications has led to 
a decrease in the occurrence of the hepatosplenic form of schistosomiasis and a similar impact has been seen on the occurrence of schistosomal glomerulopathy (Correia et al. 1997). This change in the frequency of schistosomal glomerulopathy may be reflected in the change in the distribution of glomerular lesions associated with nephrotic syndrome in adults (over 15 years old) that was reported by Queiroz et al. (1973) between 1970-1973 and that we noted in a study conducted between 2003-2006 (Fig. 2). Membranoproliferative glomerulonephritis was the most prevalent renal lesion observed in adult patients with nephrotic syndrome in the study by Queiroz et al. (1973). In our study, focal segmental glomerulosclerosis was the predominant pattern of disease in this group of patients. Furthermore, a survey carried out by the Renal Pathology Services at the Gonçalo Moniz Research Centre-Fiocruz (Salvador, Brazil) revealed a decline in the occurrence of the report of $S$. mansoni infection in biopsy request forms from 2-16\% between 2003-2009 (Table II). Positive results for S. mansoni infection were reported for 24/689 (4\%) patients and hepatosplenomegaly was reported in only one of these patients. Among the whole group of patients who tested positive for $S$. mansoni infection, 7/24 had focal segmental glomerulosclerosis and 4/24 had membranoproliferative type I glomerulonephritis (including the patient with reported hepatosplenomegaly). This prevalence of focal segmental glomerulosclerosis is quite different from that reported in a study performed in 1973 (Brito 1973) using biopsies of patients with different clinical forms of schistosomiasis (Table III). Membranoproliferative glomerulonephritis was the predominant pattern of renal lesion found by Brito (1973) in a group of patients with different clinical forms of schistosomiasis. Although these changes in the distribution of glomerular lesions may be the result of various biases related to the selection of subjects for
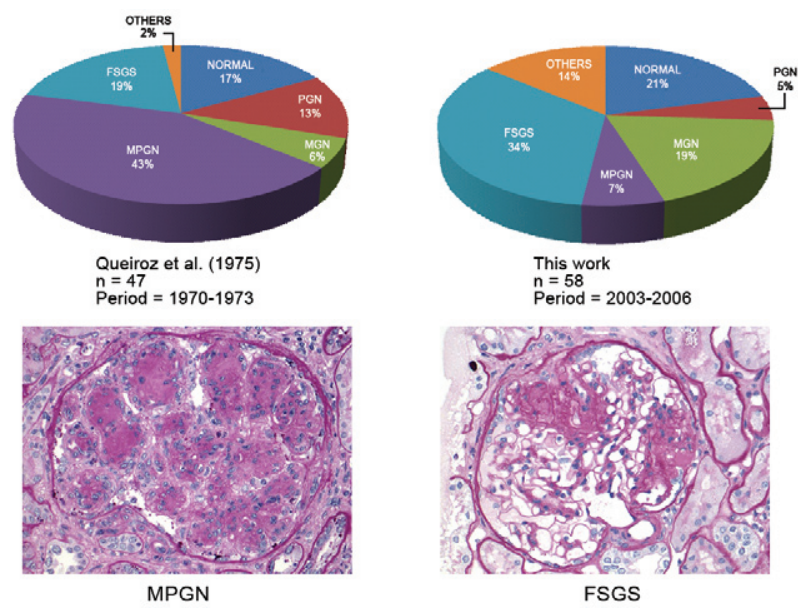

Fig. 2: changes in the distribution of renal lesions associated with nephrotic syndrome in adults in biopsies performed in public hospitals of Salvador, Bahia, during different periods. The histological images represent the most prevalent glomerulopathies observed during each period. FSGS: focal segmental glomerulosclerosis; GN: glomerulonephritis; MGN: membranous GN; MPGN: membranoproliferative GN; PGN: diffuse proliferative GN. biopsy, they may reflect actual changes in the pattern of distribution of glomerulopathies in the state of Bahia (BA), Brazil. The studies compared here all represent patients from the public general hospitals.

Changes in the distribution of glomerular diseases have been associated with socioeconomic development in many studies (Ben Maiz et al. 2006, Gusbeth-Tatomir et al. 2006, Woo et al. 2010). A biopsy-based study from Romania found a higher prevalence of membranoprolif-

\section{TABLE II}

Schistosoma mansoni infection in patients subjected to renal biopsies in public hospitals in Salvador, Bahia, during the period from 2003-2009

\begin{tabular}{lcccc}
\hline & & \multicolumn{2}{c}{ S. mansoni infection } & \\
\cline { 3 - 4 } Year & Biopsies & $\begin{array}{c}\text { Suspected } \\
\mathrm{n}(\%)\end{array}$ & $\begin{array}{c}\text { Positive } \\
\mathrm{n}(\%)\end{array}$ & $\begin{array}{c}\text { MPG } \\
\mathrm{n}(\%)\end{array}$ \\
\hline 2003 & 50 & $8(16)$ & $7(14)$ & $2(4)$ \\
2004 & 49 & $11(22)$ & $5(10)$ & $0(0)$ \\
2005 & 67 & $4(6)$ & $2(3)$ & $1(3)$ \\
2006 & 122 & $7(7)$ & $6(5)$ & $2(3)$ \\
2007 & 142 & $5(4)$ & $3(2)$ & $7(6)$ \\
2008 & 121 & $0(0)$ & $0(0)$ & $9(8)$ \\
2009 & 138 & $3(2)$ & $1(1)$ & $6(4)$ \\
\hline Total & 689 & $38(6)$ & $24(4)$ & $27(4)$ \\
\hline
\end{tabular}

MPG: membranoproliferative glomerulonephritis.

\section{TABLE III}

Changes in the distribution of renal lesions associated with different clinical forms of schistosomiasis in Salvador, Bahia, during two different periods

\begin{tabular}{lcc}
\hline Histology & $\begin{array}{c}\text { Brito (1973) } \\
\mathrm{n}(\%)\end{array}$ & $\begin{array}{c}\text { This work } \\
\mathrm{n}(\%)\end{array}$ \\
\hline $\begin{array}{l}\text { Minimal } \\
\text { glomerular changes }\end{array}$ & $9(24)$ & $2(9)$ \\
$\begin{array}{l}\text { Diffuse proliferative } \\
\text { glomerulonephritis }\end{array}$ & $0(0)$ & $2(9)$ \\
$\begin{array}{l}\text { Focal proliferative } \\
\text { glomerulonephritis }\end{array}$ & $5(13)$ & $0(0)$ \\
$\begin{array}{l}\text { IgA nephropathy } \\
\text { Membranous } \\
\text { glomerulonephritis }\end{array}$ & $\mathrm{ND}$ & $1(5)$ \\
$\begin{array}{l}\text { Membranoproliferative } \\
\text { glomerulonephritis }\end{array}$ & $2(5)$ & $3(14)$ \\
$\begin{array}{l}\text { Focal and segmental } \\
\text { glomerulosclerosis }\end{array}$ & $7(18)$ & $4(18)$ \\
\hline \begin{tabular}{l} 
Total \\
\hline
\end{tabular} & $38(100)$ & $21(100)$
\end{tabular}

ND: not determined. 
erative glomerulonephritis in the most socioeconomically deprived areas of the country than in more socioeconomically developed areas (Gusbeth-Tatomir et al. 2006). It is interesting to note that, as shown in Table II, the average frequency of membranoproliferative glomerulonephritis remained stable, comprising $4 \%$ of the biopsies in the period between 2003-2009. However, the disease most commonly associated with this pattern of glomerulonephritis during that period was systemic lupus erythematosus. None of the 13 patients for whom serological tests for hepatitis $\mathrm{B}$ and $\mathrm{C}$ viruses were available had positive results for infection.

Taken together, the data presented herein support the idea that the reduction in the occurrence of schistosomal glomerulopathy represents a change in the distribution of nephropathies in BA, toward a pattern similar to that observed in socioeconomically developed regions of the world (Korbet et al. 1996).

\section{ACKNOWLEDGEMENTS}

To Dr Zilton Andrade, for the suggestions to the manuscript.

\section{REFERENCES}

Abdul-Fattah MM, Yossef SM, Ebraheem ME, Nasr ME, Hassan MA, Abdul Wahab SE 1995. Schistosomal glomerulopathy: a putative role for commonly associated Salmonella infection. J Egypt Soc Parasitol 25: 165-173.

Andrade ZA, Andrade SG, Sadigursky M 1971. Renal changes in patients with hepatosplenic schistosomiasis. Am J Trop Med Hyg 20: 77-83.

Andrade ZA, de Queiroz AC 1968. Renal lesions in hepatosplenic schistosomiasis. Rev Inst Med Trop Sao Paulo 10: 36-40.

Andrade ZA, Susin M 1974. Renal changes in mice infected with Schistosoma mansoni. Am J Trop Med Hyg 23: 400-403.

Barsoum R 2004. The changing face of schistosomal glomerulopathy. Kidney Int 66: 2472-2484.

Bassily S, Farid Z, Barsoum RS, Soliman LA, Higashi GI, Miner WF 1976. Renal biopsy in Schistosoma-Salmonella associated nephrotic syndrome. J Trop Med Hyg 79: 256-258.

Ben Maiz H, Abderrahim E, Ben Moussa F, Goucha R, Karoui C 2006. Epidemiology of glomerular diseases in Tunisia from 1975 to 2005. Influence of changes in healthcare and society. Bull Acad Natl Med 190: 403-416.

Brito E 1973. Patologia renal na esquistossomose mansônica hepatoesplênica: Um estudo em material de biópsia renais, MSs Thesis, UFBA, Salvador, 116.

Cavallo T, Galvanek EG, Ward PA, von Lichtenberg F 1974. The nephropathy of experimental hepatosplenic schistosomiasis. Am J Pathol 76: 433-450.

Chisty MM, Nargis M, Sato H, Inaba T, Takahashi G, Kamiya H 2002. Schistosoma mansoni: kinetics of glomerulonephritis in Mongolian gerbils and its correlation with intensity and duration of infection. Parasite 9: 143-151.

Correia EI, Martinelli RP, Rocha H 1997. Is glomerulopathy due to schistosomiasis mansoni disappearing? Rev Soc Bras Med Trop 30: 341-343.

De Brito T, Gunji J, Camargo ME, Ceravolo A, Da Silva LC 1971. Glomerular lesions in experimental infections of Schistosoma mansoni in Cebus apella monkeys. Bull World Health Organ 45: 419-422.

Falcao HA, Gould DB 1975. Immune complex nephropathy and schistosomiasis. Ann Intern Med 83: 148-154.
Gusbeth-Tatomir P, Ardeleanu S, Covic M, Caruntu ID, Volovat C, Covic A 2006. Epidemiology of biopsy-proven renal disease in Romania: data from a regional registry in north-eastern Romania. Rev Med Chir Soc Med Nat Iasi 110: 540-547.

Hoshino-Shimizu S, de Brito T, Canto AL, Kanamura HY, da Silva LC 1975. Detection of schistosomal antigen (S. mansoni) in human kidneys obtained at autopsy (preliminary report). Rev Inst Med Trop Sao Paulo 17: 394-397.

Jones CE 1977. Schistosoma japonicum: anti-DNA responses, serum cryogelatification, and cryoprecipitation phenomena in infected rabbits. Exp Parasitol 42: 261-273.

Korbet SM, Genchi RM, Borok RZ, Schwartz MM 1996. The racial prevalence of glomerular lesions in nephrotic adults. Am J Kidney Dis 27: 647-651.

Lopes AA, Port FK, James SA, Silveira MA, Martinelli R, Brito E, Rocha H 2002. Race and glomerulonephritis in patients with and without hepatosplenic Schistosomiasis mansoni. Clin Nephrol 58: 333-336.

Martinelli R, Pereira LJ, Brito E, Rocha H 1992. Renal involvement in prolonged Salmonella bacteremia: the role of schistosomal glomerulopathy. Rev Inst Med Trop Sao Paulo 34: 193-198.

Queiroz FP, Brito E, Martinelli R 1975. Influence of regional factors in the distribution of the histologic patterns of glomerulopathies in the nephrotic syndrome. Nephron 14: 466-470.

Queiroz PF, Brito E, Martinelli R, Rocha H 1973. Nephrotic syndrome in patients with Schistosoma mansoni infection. Am J Trop Med Hyg 22: 622-628.

Ramos EA, Andrade ZA 1987. Chronic glomerulonephritis associated with hepatosplenic Schistosomiasis mansoni. Rev Inst Med Trop Sao Paulo 29: 162-167.

Rocha H, Cruz T, Brito E, Susin M 1976. Renal involvement in patients with hepatosplenic Schistosomiasis mansoni. Am J Trop Med Hyg 25: 108-115.

Rodrigues VL, Otoni A, Voieta I, Antunes CM, Lambertucci JR 2010. Glomerulonephritis in schistosomiasis mansoni: a time to reappraise. Rev Soc Bras Med Trop 43: 638-642.

Sadigursky M, Andrade ZA 1976. Renal amyloidosis and schistosomiasis. Br Med J 2: 1073.

Sobh M, Moustafa F, el-Arbagy A, el-Din MS, Shamaa S, Amer G 1990. Nephropathy in asymptomatic patients with active Schistosoma mansoni infection. Int Urol Nephrol 22: 37-43.

Strausbaugh LJ, Farid Z, Higashi GI, Bassily S 1978. Renal amyloidosis with nephrotic syndrome in two patients with schistosomiasis mansoni and chronic salmonellosis. Am J Trop Med Hyg 27: 919-923.

van Marck EA, Deelder AM, Gigase PL 1977. Effect of partial portal vein ligation on immune glomerular deposits in Schistosoma mansoni-infected mice. Br J Exp Pathol 58: 412-417.

van Marck EA, Deelder AM, Gigase PL 1981. Schistosoma mansoni: anodic polysaccharide antigen in glomerular immune deposits of mice with unisexual infections. Exp Parasitol 52: 62-68.

van Marck EA, Jacob W, Deelder AM, Gigase PL 1979. Experimental schistosomal glomerulopathy in mice and its relation to portosystemic collateral circulation. A light and electron microscope study. Ann Soc Belg Med Trop 59: 33-47.

Woo KT, Chan CM, Mooi CY, H. LC, Tan HK, Foo M, Lee GS, Anantharaman V, Lim CH, Tan CC, Lee EJ, Chiang GS, Tan PH, Boon TH, Fook-Chong S, Wong KS 2010. The changing pattern of primary glomerulonephritis in Singapore and other countries over the past 3 decades. Clin Nephrol 74: 372-383.

Zeid AM, Hassan MM, Attia WM, el-Desouky AI, Badawy AM, Aly AS 1994. Hepatitis-B virus and schistosomiasis infections in childhood proteinuria. J Egypt Soc Parasitol 24: 371-382. 